\title{
Temporary External Fixation to Table as a Traction Reduction Aide in the Treatment of Unstable Pelvic Ring Injuries: A Technical Note
}

\author{
Filippo Romanelli, DO, Eric Boe, D0, Li Sun, DO, David M. Keller, D0, \\ Richard S. Yoon, MD, Frank A. Liporace, MD \\ Division of Orthopaedic Trauma \& Adult Reconstruction, Department of Orthopaedic Surgery, \\ Jersey City Medical Center - RWJBarnabas Health, Jersey City, NJ, USA
}

Displaced pelvic ring injuries can be challenging to even the experienced orthopedic traumatologist. A temporary external fixation to table construct provides a quick, simple, and accessible means of external skeletal fixation to reliably obtain and maintain stable hemipelvis reduction on the operating room table. The contralateral hemipelvis can be stabilized to the table by use of Steinman pins safely inserted into the subtrochanteric and anterior column regions and later connected to external fixator bars attached to the table. With rigid stabilization, the displaced contralateral pelvic fragment(s) can be reduced in a more vector intentional manner with greater force than the traditional means of pelvic reduction can allow. The skeletal-table fixation technique is presented along with two cases, a combined pelvic-acetabular injury and an isolated pelvic ring injury.

Key Words: Pelvis, External fixators, Fracture fixation

\section{INTRODUCTION}

Unstable pelvic ring injuries can present unique and clinically challenging scenarios, especially when presented with significant vertical displacement or concomitant acetabular

Submitted: July 25, 2020 1st revision: August 21, 2020

2nd revision: August 28, 2020 Final acceptance: August 28, 2020

Address reprint request to

Richard S. Yoon, MD

(https://orcid.org/0000-0001-5240-6633)

Division of Orthopaedic Trauma \& Adult Reconstruction, Department of Orthopaedic Surgery, Jersey City Medical Center - RWJBarnabas Health, 377 Jersey Ave, Suite 280A, Jersey City, NJ 07302, USA

TEL: +1-201-716-5850 FAX: +1-201-915-2424

E-mail: yoonrichdgmail.com

This is an Open Access article distributed under the terms of the Creative Commons Attribution Non-Commercial License (http://creativecommons. org/licenses/by-nc/4.0) which permits unrestricted non-commercial use, distribution, and reproduction in any medium, provided the original work is properly cited fractures. The use of a temporary external fixation to table (eXFT) construct as a reduction aide in the operative fixation of pelvic ring injuries has allowed for efficient reduction and treatment, adding to the traumatologists treatment $\operatorname{armamentarium}^{1-3)}$. Obtaining counter-traction to reduce a displaced hemipelvis can be achieved via a perineal post or via the use of pre-fabricated frames ${ }^{4,5)}$. However, a perineal post can often allow for pelvic malrotation and has the potential to cause pudendal nerve compression. A prefabricated skeletal frame that attaches to the table can avoid rotation and pudendal nerve injury, though availability and high cost can be prohibitive factors ${ }^{5}$.

This technical note article presents the use of a temporary method of achieving appropriate contralateral hemipelvic countertraction with external fixation pins placed within the contralateral side of the pelvis that needs to be reduced. These pins can be readily clamped to any radiolucent table utilizing reusable external fixation bars and clamps that are available to all orthopedists. Inexpensive, while avoiding 


\section{Hip \& Pelvis}

Filippo Romanelli et al. Temporary Traction Reduction Aide in Treatment of Unstable Pelvis Injuries

pudendal nerve injury and undesired rotation, the eXFT technical note is often utilized in the authors' institution. Here, the use of eXFT in a combined pelvic-acetabular injury and an isolated pelvic ring injury is described, however this method can be extrapolated for use in any scenario where countertraction is desired as a pelvic ring reduction aide.

\section{TECHNIQUE AND CASE PRESENTATIONS}

\section{Technique}

The patient is placed supine on a radiolucent fracture table with or without perineal post. Distal extremity traction can be applied via the fracture table boot or skeletal traction via distal extremity pins to the affected side as needed. Prior to draping, a $6.0 \mathrm{~mm}$ self-tapping partially threaded Schanz pin is first placed under sterile conditions in the subtrochanteric region laterally at a level inferior to the lesser trochanter to avoid creation of a stress riser for future fracture. Anatomical start point is verified fluoroscopically. A small stab skin incision is made and the Schanz pin is inserted into bone and centered by tactile feedback confirming anterior and posterior cortex. An anterior to posterior (AP) image is taken prior to drilling the pin bi-cortically and confirmed (Fig. 1A). Next, the second $6.0 \mathrm{~mm}$ pin is placed into the anterior third of the iliac crest and the gluteus medius pillar of the anterior column. The iliac crest is palpated starting two fingerbreadths posterior to the anterior superior iliac spine to avoid injury to the lateral femoral cutaneous nerve. A percutaneous stab incision is made and carried down to bone.
The gluteus medius tubercle start point is confirmed fluoroscopically utilizing pelvic outlet views. The pin can be driven through the middle third of the iliac crest on an outlet view while maintaining the roughly 24 degrees from vertical trajectory to remain within the iliac table ${ }^{6}$. A T-handle can be utilized to advance the pin in a distal, medial, and posterior direction to reduce the risk of cortical penetration outside of the iliac table (Fig. 1B). These locations were chosen for their strong corridors, availability, and ease. The subtrochanteric pin prevents distal displacement while the iliac crest pin prevents pelvic rotation and tilt around a stable femoral head. Next, external fixation clamps and radiolucent bars are attached to the $6.0 \mathrm{~mm}$ Schanz pins, which can be connected to the fracture table via position clamps in various triangulated arrangements for additional stability (Fig. 2 ). The required instrumentation along with a skeletal representation of the construct is shown (Fig. 3, 4).

Fixation clamps should be placed as close to the skin as possible for increased stability. At this juncture, temporary or definitive percutaneous supra acetabular or iliac crest pins can be placed to the injured side so effective manual reduction can be performed as movement of the intact hemipelvis is minimized. Once reduction has been achieved it can be maintained with the introduction of additional clamps and bars to link both hemipelvis' or trans sacral screws to close any posterior diastasis that exists. Pins are then re-prepped and draped in the surgical field.
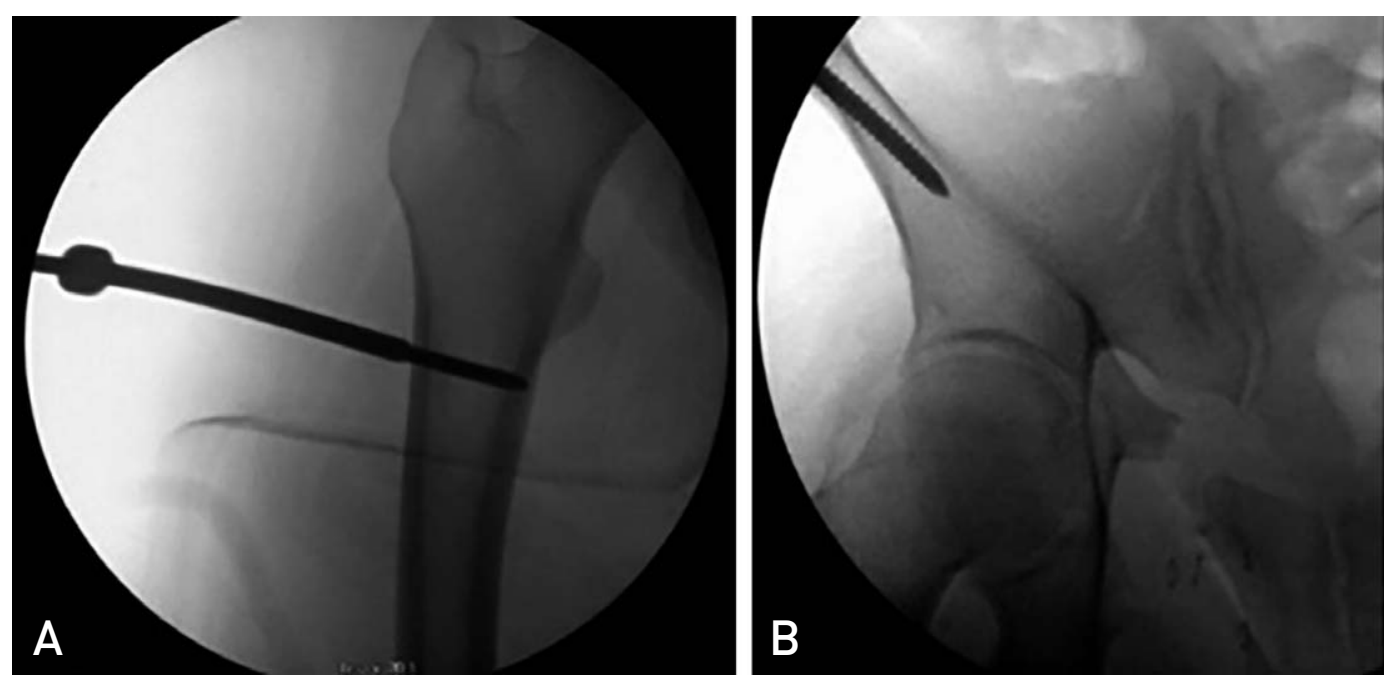

Fig. 1. Placement of Steinmann pins. (A) Anterior column pin directed distally, medially, and posteriorly, starting at the gluteus medius tubercle. (B) Subtrochanteric pin. 


\section{Hip \& Pelvis}

Hip Pelvis 32(4): 214-222, 2020
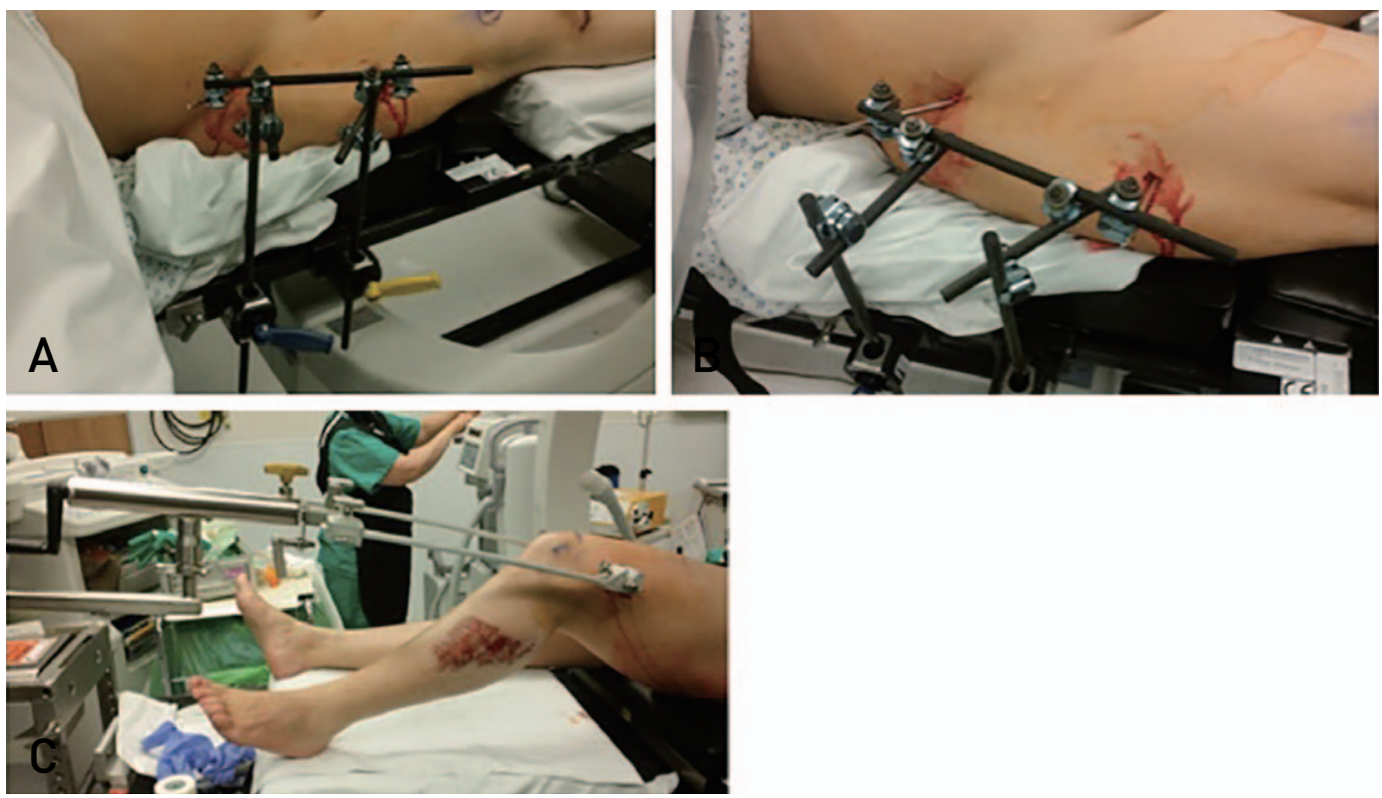

Fig. 2. (A, B) Supine positioning following Steinman pin placement to Rt femur and pelvis, external fixation clamps and fiberglass bars are attached to the table by position clamps. (C) The left leg was placed in skeletal traction adjusted by the table's gross and fine traction bar for anatomical reduction.
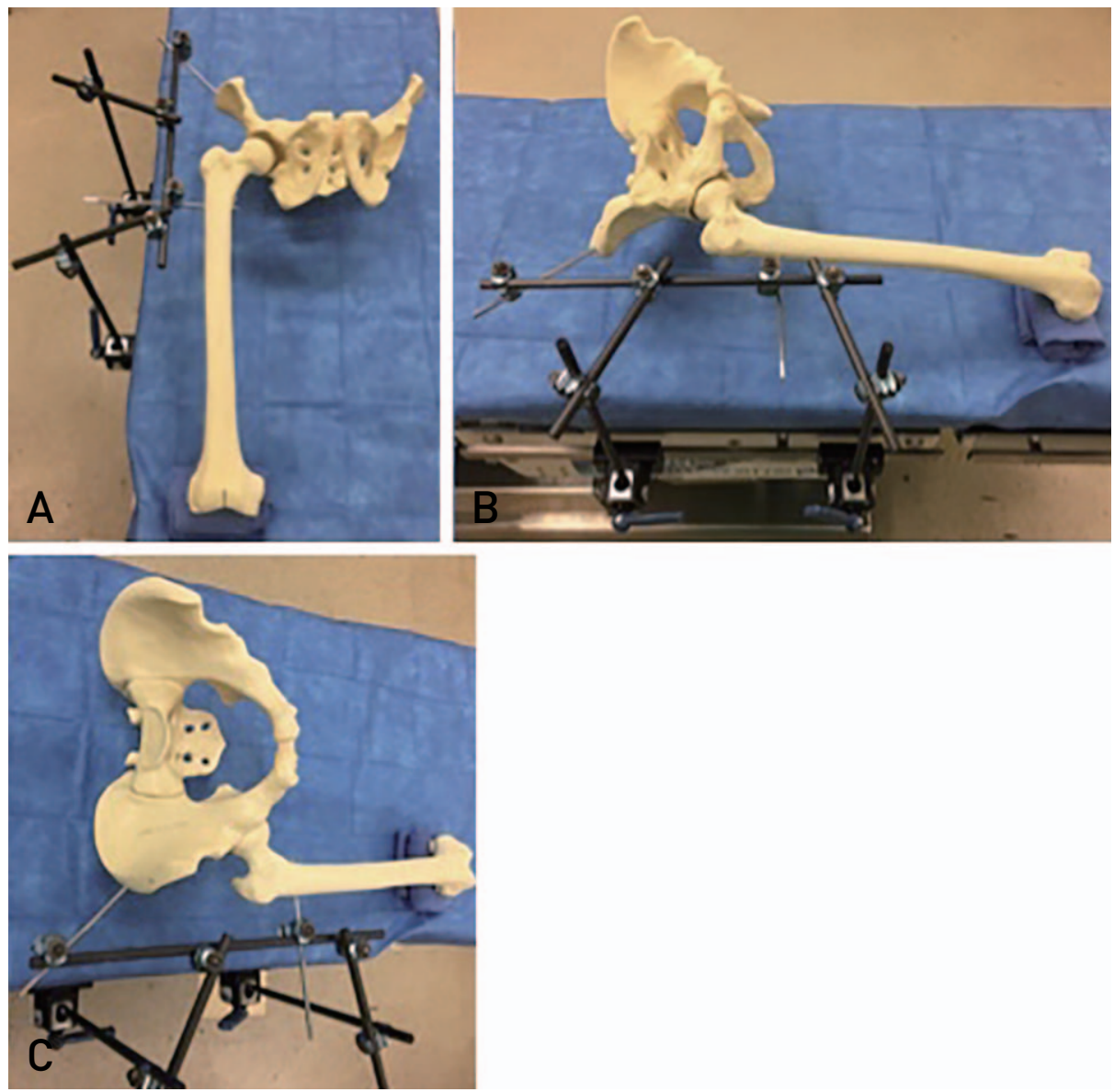

Fig. 3. Table-skeletal external fixator constructs. 


\section{Hip \& Pelvis}

Filippo Romanelli et al. Temporary Traction Reduction Aide in Treatment of Unstable Pelvis Injuries
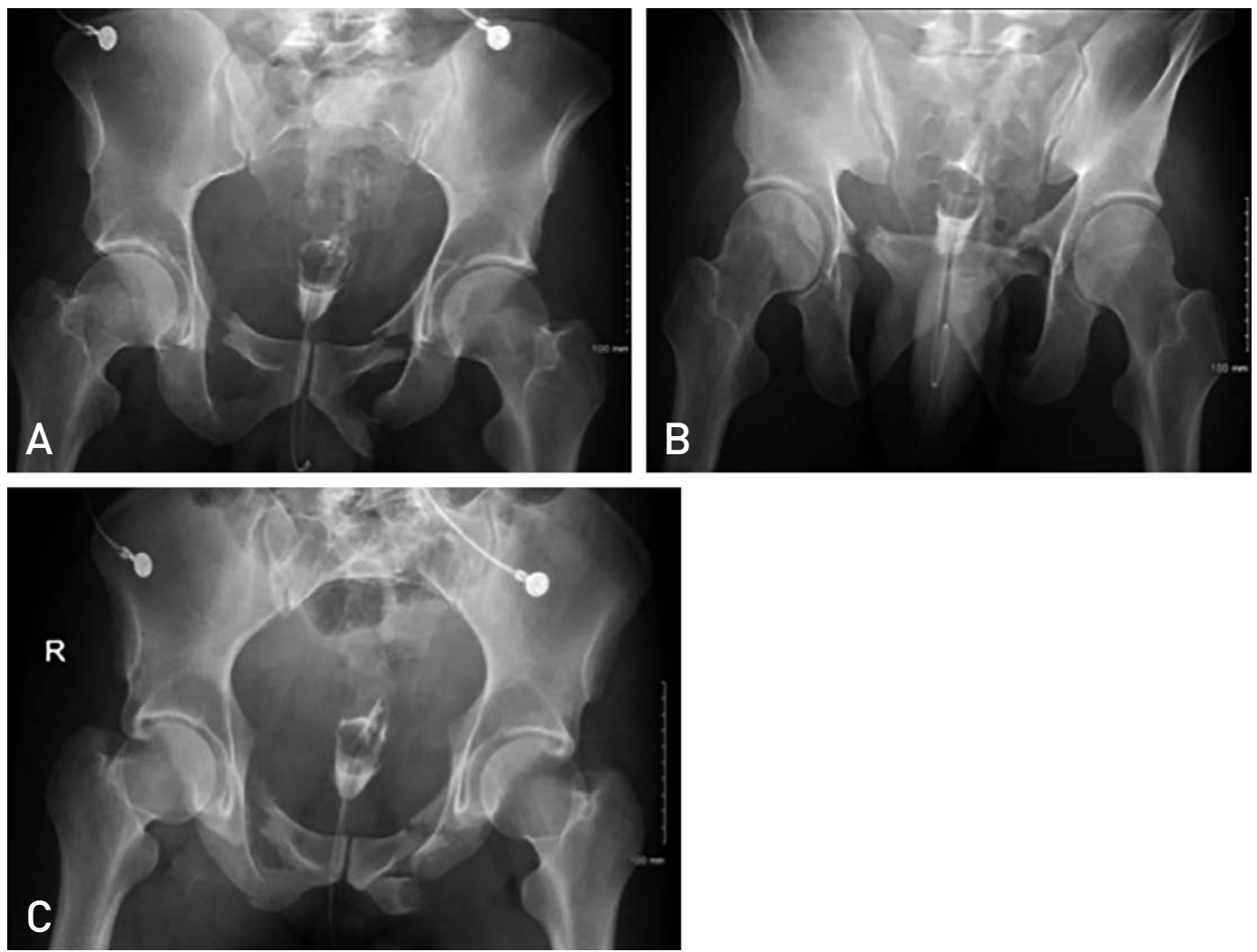

Fig. 4. Severe traumatic windswept lateral compression injury in a 24-year-old male.

\section{Case Presentation}

\section{1) Case 1 - Combined Mechanism Pelvic Fracture: LC Type III + Vertical Shear}

A 24-year-old male motorcyclist was involved in a motor vehicle collision sustaining a combined mechanism pelvic ring fracture with a left type III lateral compression and mild vertical shear component in addition to bilateral superior and inferior rami fractures (Fig. 5). Due to the patient's relatively superior displaced left hemipelvis, the patient was placed in skeletal traction via the use of a distal femoral distraction pin. After stabilization, the patient was sent to the operating room for bilateral posterior ring percutaneous sacro-iliac screw fixation and definitive anterior supra-acetabular external ex-fix fixation (Fig. 6). The patient was positioned supine with perineal post as described. The right hemipelvis was then stabilized to the table using the eXFT technique. Skeletal traction was applied to the left lower extremity with gross and fine traction adjustments (Fig. 2C) until vertical reduction was achieved as confirmed by pelvic outlet view. A right percutaneous S1 sacro-iliac screw was then placed through the ilium into the sacrum and confirmed radiographically utilizing the lateral of the sacrum, inlet and outlet views to be in the correct corridor without violation to the sacral ala. Having vertical control, attention was turned to internal/external rotation deformity. A left supra acetabular pin was placed using a combination of the iliac oblique, outlet obturator oblique, and inlet obturator oblique views. The iliac oblique was first utilized to identify the entry point at the level of the anterior inferior iliac spine (AIIS) and to ensure the trajectory above the sciatic notch. Next, the outlet obturator oblique was used to avoid violation of the joint capsule by staying superior within the corridor to ensure remaining superior to the most proximal joint capsule attachments. Lastly, the inlet obturator oblique was utilized to confirm proper trajectory within the table of the sciatic buttress ${ }^{7}$. The left supraacetabular pin was then used to manually manipulate the relatively internally rotated left hemipelvis with fine-tuning of the anterior/posterior rotation about the S1 screw axis. Anterior external fixation bars were used to lock the rotational reduction in place and the patient was treated definitively with external fixation (Fig. 6).

The patient was kept on a non-weight bearing protocol and treated in the external fixator for 3 months and followed for 1 year. The patient was allowed to begin range of motion exercises to his hips and core with physical therapy in the 


\section{Hip \& Pelvis}

Hip Pelvis 32(4): 214-222, 2020
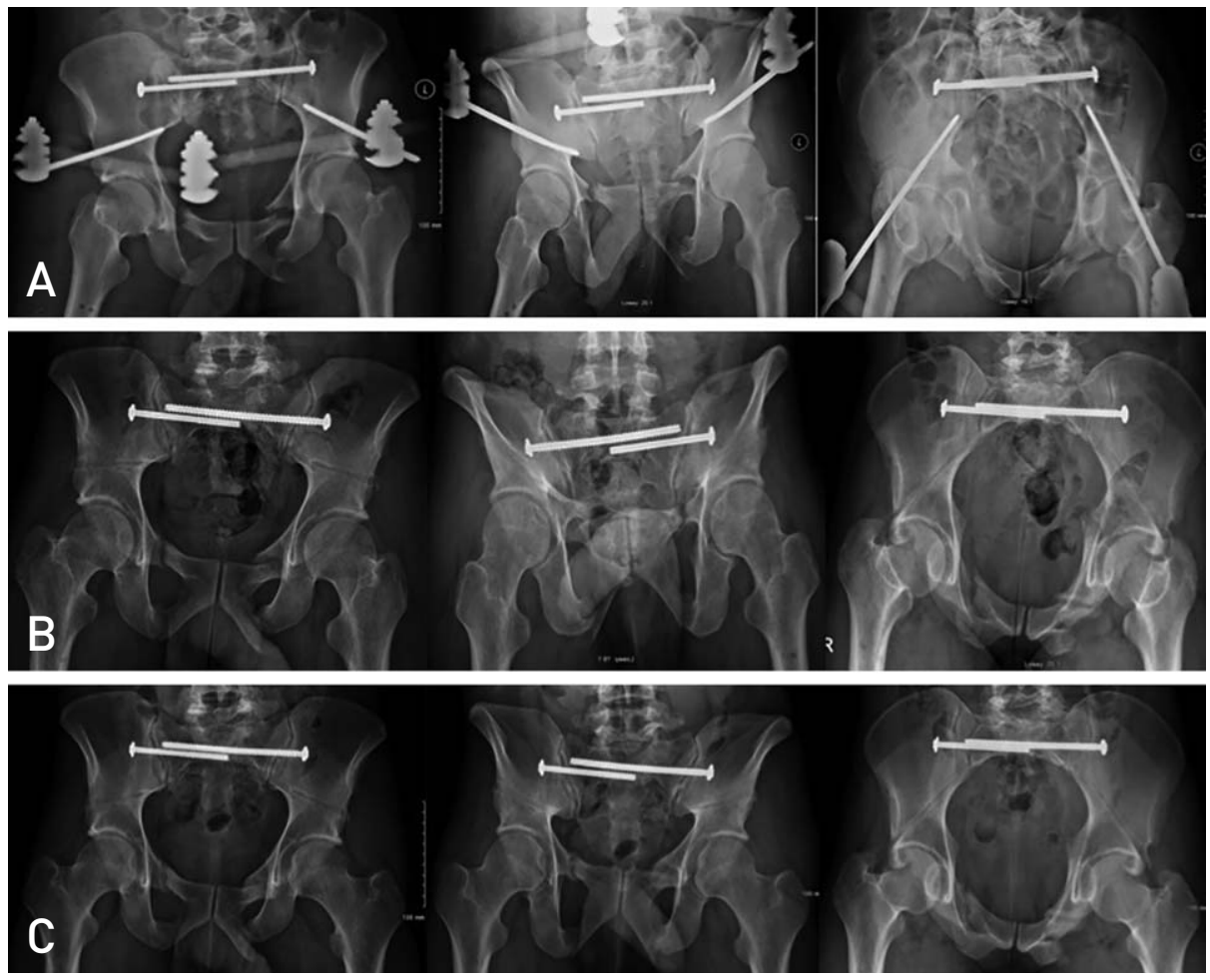

Fig. 5. (A) Post-definitive fixation radiographs following the use of the Table-Skeleton technique and supraacetabular external fixation pin placement with inlet and outlet radiographs. (B) 3 months postoperative after ex-fix removal. (C) 6 months postoperative.
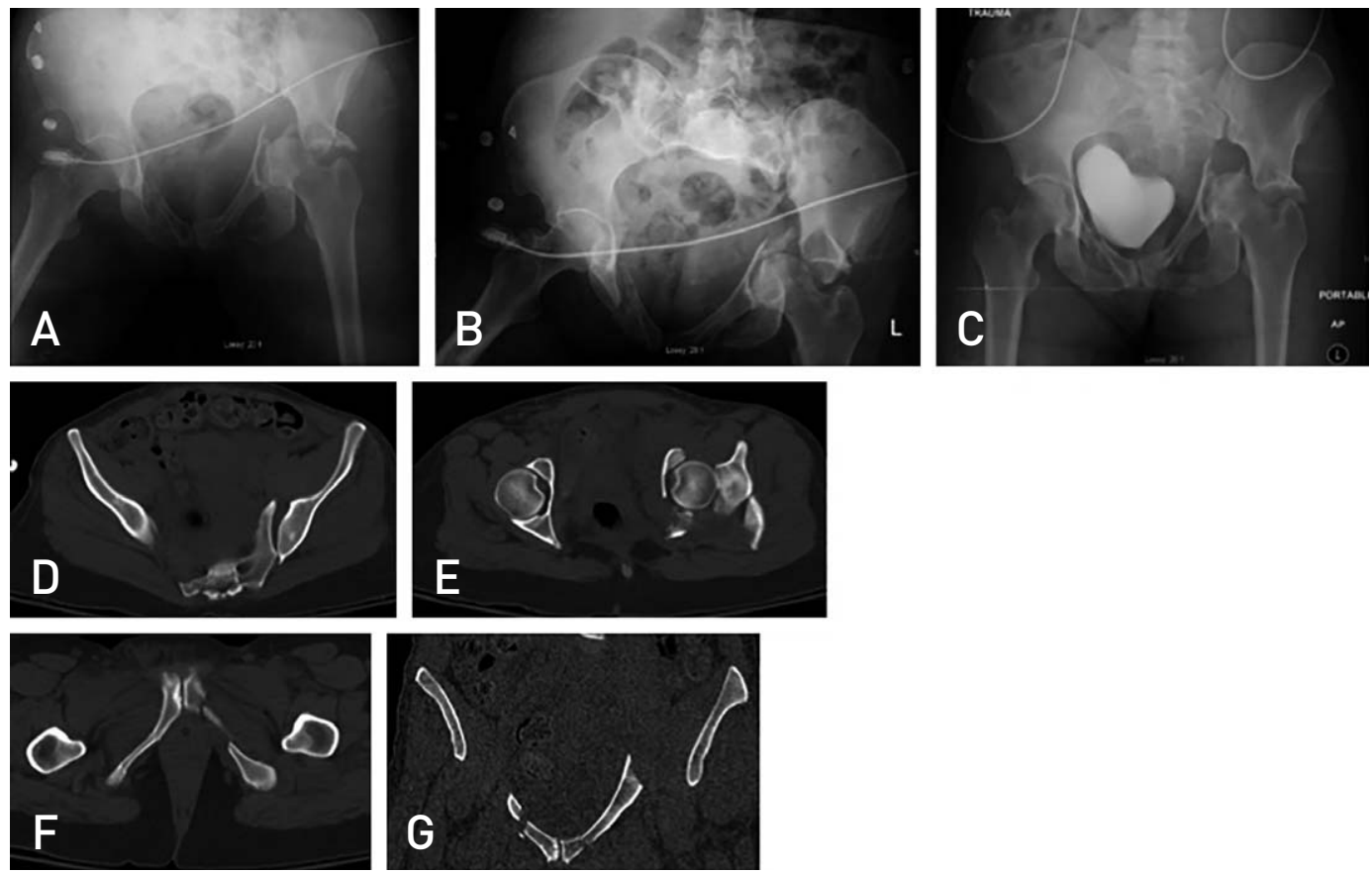

Fig. 6. Traumatic lateral compression injury in a 37-year-old female with a displaced, concomitant T-type acetabular fracture. Note the left-sided illiosacral diastasis. 


\section{Hip\& Pelvis}

Filippo Romanelli et al. Temporary Traction Reduction Aide in Treatment of Unstable Pelvis Injuries

immediate post-operative period as tolerated. The patient reported lumbar spine tightness within the initial 1 month of external fixator removal which resolved by the 6th month follow-up. The patient was followed for 1 year with no complications or limitations in function.

\section{2) Case 2 - T-type Acetabular Frature/Femoral} Head Dislocation with Sacroiliac Joint Diastasis

A 37-year-old female pedestrian was struck and run over by a vehicle causing a right lateral compression, left T-type acetabulum fracture with femoral head dislocation in addition to left anterior sacroiliac diastasis (Fig. 7). The patient was initially hemodynamically unstable with pulmonary injuries requiring chest tube placement and multiple blood product transfusions. Damage control care was implemented, and the patient acutely underwent a closed reduction of the left femoral head dislocation and was placed in skeletal traction until stabilized to appropriate lactate and hemodynamic parameters.

The patient was taken to the operating room on her 4th hospital day. Given the complex nature of this pelvic ring and acetabular injury, both anterior and posterior approaches were utilized ${ }^{8-11}$. The patient was placed supine on a radiolucent Jackson flat table outfitted with skeletal traction attachments without a perineal post. Due to the degree of the acetabular comminution and obstruction to the anterior acetabular approach the perineal post could not be used for traction. Alternatively, the patient's right hemipelvis was stabilized to the Jackson table utilizing the described eXFT technique. The left femoral traction was then fine-tuned to achieve proper length. The left iliac wing was manually manipulated and reduced to the stable right hemipelvis. A partially threaded $7.3 \mathrm{~mm}$ cannulated percutaneous screw was placed through the left ilium perpendicular to the sacro-iliac joint into the S1 sacral body with fluoroscopic aid utilizing inlet, outlet, and lateral views ${ }^{12-15)}$. After posterior stabilization, attention was turned to reconstruction of the anterior ring and column utilizing a modified Stoppa approach with a left lateral window ${ }^{16}$. Dissection was carried down to the superior rami bilaterally. Bilateral corona mortis anastomoses were encountered, ligated and mobilized. The right anterior ring was first fixed with a custom contoured 10-hole pelvic reconstruction plate. The left anterior ring was stabilized in the same manner utilizing a 14hole custom contoured reconstruction plate with care not to violate the joint with screw fixation. The incision was irrigated and closed and attention was turned to the acetabular fracture.

The patient was placed in a lateral position and posterior approach was performed through an extensile Kocher-
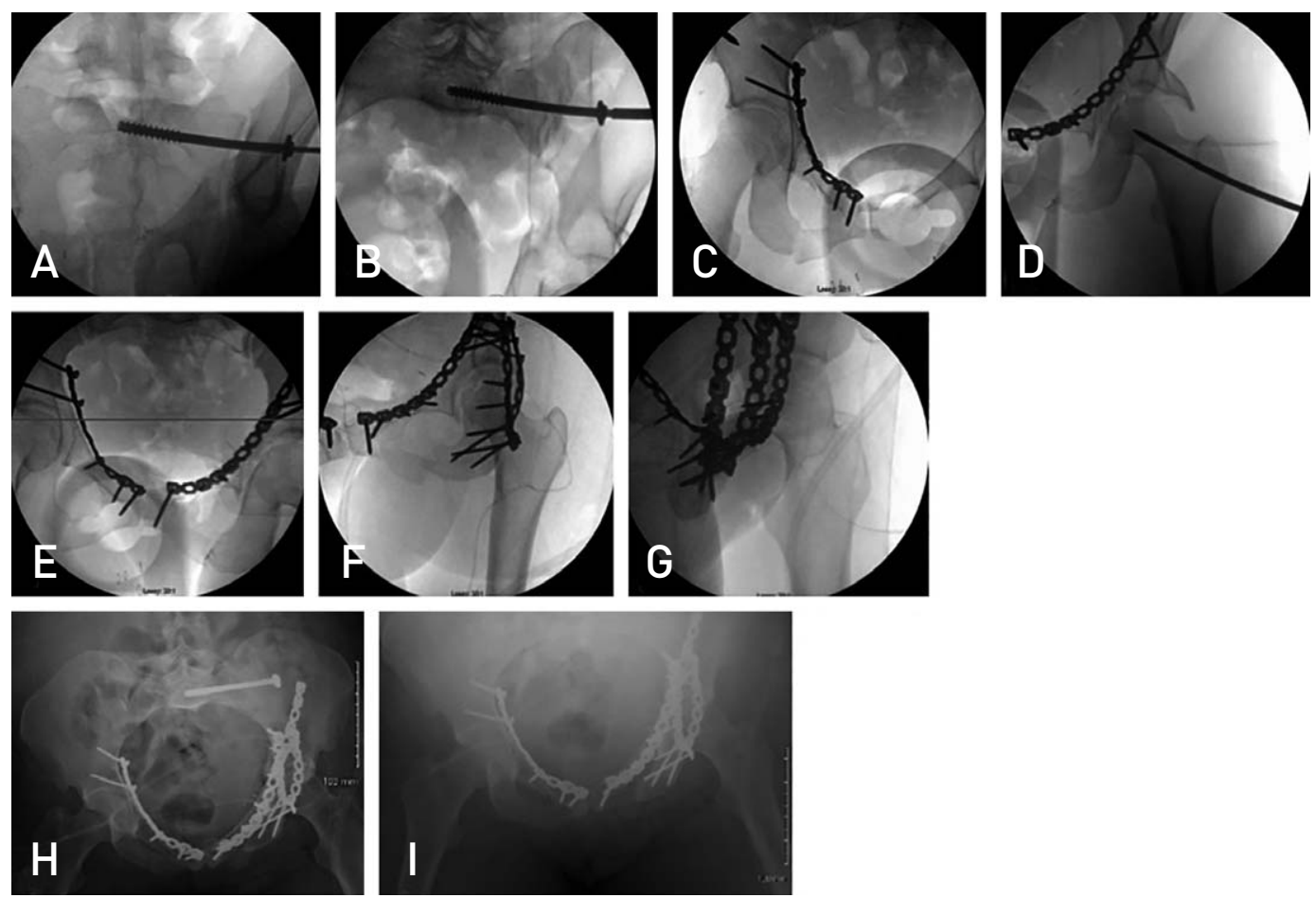

Fig. 7. Post-definitive fixation radiographs following use of the Table-Skeleton technique for contralateral hemipelvis stabilization. 
Langenbeck approach ${ }^{17)}$. The segmental posterior column injury and large posterior wall fragments were provisionally held in position with bone reduction clamps and K-wires. Both a 7-hole and 8-hole $3.5 \mathrm{~mm}$ pelvic reconstruction plate were custom contoured to the patient's acetabulum with lag screws into the posterior wall fragment. AP pelvis, inlet, outlet and judet view were obtained to confirm the proper positioning of all implants. Definitive open reduction, internal fixation was performed (Fig. 7).

Using eXFT as a traction aide in these unstable pelvic ring injuries brought sufficient biomechanical stability with proper reduction while avoiding malrotation in preparation for definitive pelvic fixation. We have achieved satisfactory anatomic pelvic reduction when utilizing this technique as a reduction aide in ten patients. No complications were noted including pin site infection, pin site fracture, fracture displacement or malrotation, or neurovascular injury. Postoperatively, all fractures healed without any reoperation.

\section{DISCUSSION}

Pelvic fractures are relatively common but serious injuries representing nearly $5 \%$ of trauma admissions and are associated with an approximate $8 \%$ mortality rate ${ }^{18,19}$. While the morbidity and mortality related to these injuries still exist, our knowledge and approach regarding proper management and treatment of these injuries continue to improve. It is generally accepted that nonoperative management of unstable pelvic fractures yields poor results ${ }^{20-25}$, while early anatomic reduction and stabilization of such injuries lead to superior patient outcomes ${ }^{26-28}$. A variety of percutaneous pelvic pin positions in the management of similar pelvic injuries have been described ${ }^{4,1529-32}$. Our decision to utilize the subtrochanteric and anterior column locations for pin placement was based on predictable, reliable, and safe locations with strong osseous corridors.

Operative fixation of pelvic ring injuries with and without concomitant acetabular fractures are technically challenging clinical scenarios. While anatomic reduction is the fundamental and ultimate goal of treatment, the complex threedimensional shape of the pelvis, along with the multiplanar nature of displacement and difficult anatomical access all contribute to challenging fixation. Especially in the setting of concomitant acetabular fracture and/or vertical hemipelvic displacement, reduction tools and technical notes can help make operative fixation more efficient and facile. Our table skeletal fixation method can be utilized in the treatment of complex pelvic ring injuries ${ }^{33)}$ with or without associated acetabular fracture ${ }^{34,35}$. Though not described here, utilization of the eXFT may be extrapolated for posterior patient positioning with pins placed through the posterior superior iliac spine in the sciatic buttress for posterior exposures.

With any percutaneous technique, complications may arise including misplaced guide-wires, external fixator pins, pin site infection, pin cut-out, fracture, and neurovascular injury; however, we have not observed any within our series. As traction and rotational forces are applied to the external fixator pins, we have been careful to not over-distract or overrotate the pelvis through continually monitoring fluoroscopy images. Furthermore, to decrease the risk of surgical site and pin site infections, the patient is prepped and draped utilizing sterile technique prior to pin placement. If the patient requires ipsilateral pelvic stabilization post pin placement, the external fixator pins and bars are re-prepped into the surgical window. To date, we have not observed any complications related to external fixator pin placement.

To our knowledge, no such technique has been described before in the literature. Unlike previous methods ${ }^{4,5}$, our technique does not require the additional capital investment, time or training to properly set up any specialized equipment or frames and serves as a viable alternative. Lefaivre et al. ${ }^{4}$ utilize two double half-circle frames with crossbars clamped to the edge of the bed, requiring additional steps when compared with our technique. Furthermore, the authors place a pin just superior to the acetabulum with a second pin placed from the AIIS posterior to the posterior inferior iliac spine. Depending on the deformity, an additional pin is placed within the injured side to achieve adequate reduction. Adequate reduction in a pelvis with a vertical shear component may be more difficult to achieve when utilizing this technique in comparison to having a subtrochanteric pin as in our technique. Similarly, Matta and Yerasimides ${ }^{5}$ utilize a subtrochanteric pin, however, the patient is placed in a prone position with a second pin placed in the posterior superior iliac spine of the unaffected pelvis to achieve the desired reduction of the posterior ring. The pelvic reduction frame is removed once the posterior ring is stabilized and the patient is flipped to a supine position and re-draped if anterior ring fixation is necessary. This requires additional steps, additional cost in material, and additional time within the operating room when compared to our technique. The eXFT method can be implemented with the use of any external fixation system that is already familiar to the surgeon. Furthermore, this decreases cost, as a reusable tackle box can be sterilized and used for multiple procedures. Similar 
Filippo Romanelli et al. Temporary Traction Reduction Aide in Treatment of Unstable Pelvis Injuries

to both described prefabricated fixation frames, the current technique resists vertical, horizontal, and rotational movement of the uninjured hemipelvis, through subtrochanteric and anterior column pins. The table-skeleton fixation technique achieved with the use of our existing external fixator has improved our ability to manage complex and unstable pelvic injuries and represents a simple, inexpensive, and easily accessible technique that can be readily adopted by other orthopedic traumatologists.

\section{CONFLICT OF INTEREST}

The authors declare that there is no potential conflict of interest relevant to this article.

\section{REFERENCES}

1. Bellabarba C, Ricci WM, Bolhofner BR. Distraction external fixation in lateral compression pelvic fractures. J Orthop Trauma. 2006;20(1 Suppl):S7-14.

2. Tornetta P 3rd, Templeman DC. Expected outcomes after pelvic ring injury. Instr Course Lect. 2005;54:401-7.

3. Routt ML Jr, Nork SE, Mills WJ. Percutaneous fixation of pelvic ring disruptions. Clin Orthop Relat Res. 2000;(375): 15-29.

4. Lefaivre KA, Starr AJ, Reinert CM. Reduction of displaced pelvic ring disruptions using a pelvic reduction frame. $J$ Orthop Trauma. 2009;23:299-308.

5. Matta JM, Yerasimides JG. Table-skeletal fixation as an adjunct to pelvic ring reduction. J Orthop Trauma. 2007; 21:647-56.

6. Rupp RE, Ebraheim NA, Jackson WT. Anatomic and radiographic considerations in the placement of anterior pelvic external fixator pins. Clin Orthop Relat Res. 1994;(302): 213-8.

7. Gardner MJ, Nork SE. Stabilization of unstable pelvic fractures with supraacetabular compression external fixation. J Orthop Trauma. 2007;21:269-73.

8. Routt ML Jr, Swiontkowski MF. Operative treatment of complex acetabular fractures. Combined anterior and posterior exposures during the same procedure. J Bone Joint Surg Am. 1990;72:897-904.

9. Harris AM, Althausen P, Kellam JF, Bosse MJ. Simultaneous anterior and posterior approaches for complex acetabular fractures. J Orthop Trauma. 2008;22:494-7.

10. Matta JM, Letournel E, Browner BD. Surgical management of acetabular fractures. Instr Course Lect. 1986;35:38297.

11. Matta JM. Fractures of the acetabulum: accuracy of reduction and clinical results in patients managed operatively within three weeks after the injury. J Bone Joint Surg Am. 1996;78:1632-45.

12. Osterhoff G, Ossendorf C, Wanner GA, Simmen HP, Werner CM. Percutaneous iliosacral screw fixation in S1 and S2 for posterior pelvic ring injuries: technique and perioperative complications. Arch Orthop Trauma Surg. 2011;131:809-13.

13. Shuler TE, Boone DC, Gruen GS, Peitzman AB. Percutaneous iliosacral screw fixation: early treatment for unstable posterior pelvic ring disruptions. J Trauma. 1995;38:453-8.

14. Letournel E. Pelvic fractures. Injury. 1978;10:145-8.

15. Keating JF, Werier J, Blachut P, Broekhuyse H, Meek RN, O'Brien PJ. Early fixation of the vertically unstable pelvis: the role of iliosacral screw fixation of the posterior lesion. J Orthop Trauma. 1999;13:107-13.

16. Cole JD, Bolhofner BR. Acetabular fracture fixation via a modified Stoppa limited intrapelvic approach. Description of operative technique and preliminary treatment results. Clin Orthop Relat Res. 1994;(305):112-23.

17. Braun W, Mayr E, Rüter A. [Reconstruction of complex acetabular fractures using the extensile Kocher-Langenbeck approach (modified Maryland approach)]. Oper Orthop Traumatol. 1997;9:83-96. German.

18. Yoshihara H, Yoneoka D. Demographic epidemiology of unstable pelvic fracture in the United States from 2000 to 2009: trends and in-hospital mortality. J Trauma Acute Care Surg. 2014;76:380-5.

19. Failinger MS, McGanity PL. Unstable fractures of the pelvic ring. J Bone Joint Surg Am. 1992;74:781-91.

20. Templeman DC, Simpson T, Matta JM. Surgical management of pelvic ring injuries. Instr Course Lect. 2005;54:395400.

21. Nepola JV, Trenhaile SW, Miranda MA, Butterfield SL, Fredericks DC, Riemer BL. Vertical shear injuries: is there a relationship between residual displacement and functional outcome? J Trauma. 1999;46:1024-9; discussion 1029-30.

22. Matta JM, Dickson KF, Markovich GD. Surgical treatment of pelvic nonunions and malunions. Clin Orthop Relat Res. 1996;(329):199-206.

23. Goldstein A, Phillips T, Sclafani SJ, et al. Early open reduction and internal fixation of the disrupted pelvic ring. J Trauma. 1986;26:325-33.

24. Browner BD, Cole JD, Graham JM, Bondurant FJ, NunchuckBurns SK, Colter HB. Delayed posterior internal fixation of unstable pelvic fractures. J Trauma. 1987;27:998-1006.

25. Kokubo Y, Oki H, Sugita D, et al. Functional outcome of patients with unstable pelvic ring fracture. J Orthop Surg (Hong Kong). 2017;25:2309499016684322.

26. Sharpe JP, Magnotti LJ, Gobbell WC, et al. Impact of early operative pelvic fixation on long-term self-reported outcome following severe pelvic fracture. J Trauma Acute Care Surg. 2017;82:444-50.

27. Dujardin FH, Hossenbaccus M, Duparc F, Biga N, Thomine JM. Long-term functional prognosis of posterior injuries in high-energy pelvic disruption. J Orthop Trauma. 1998;12: 145-50; discussion 150-1.

28. Tile M. Pelvic fractures: operative versus nonoperative treatment. Orthop Clin North Am. 1980;11:423-64.

29. Routt ML Jr, Kregor PJ, Simonian PT, Mayo KA. Early results of percutaneous iliosacral screws placed with the patient in the supine position. J Orthop Trauma. 1995;9:207-14.

30. Starr AJ, Jones AL, Reinert CM, Borer DS. Preliminary results and complications following limited open reduction and percutaneous screw fixation of displaced fractures of the acetabulum. Injury. 2001,32 Suppl 1:SA45-50. 


\section{Hip \& Pelvis}

Hip Pelvis 32(4): 214-222, 2020

31. Starr AJ, Reinert CM, Jones AL. Percutaneous fixation of the columns of the acetabulum: a new technique. J Orthop Trauma. 1998; 12:51-8.

32. Starr AJ, Walter JC, Harris RW, Reinert CM, Jones AL. Percutaneous screw fixation of fractures of the iliac wing and fracture-dislocations of the sacro-iliac joint (OTA Types 61B2.2 and 61-B2.3, or Young-Burgess "lateral compression type II” pelvic fractures). J Orthop Trauma. 2002;16:116-23.
33. Young JW, Burgess AR, Brumback RJ, Poka A. Pelvic fractures: value of plain radiography in early assessment and management. Radiology. 1986;160:445-51.

34. Judet R, Judet J, Letournel E. Fractures of the acetabulum: classification and surgical approaches for open reduction. Preliminary report. J Bone Joint Surg Am. 1964;46:1615-46.

35. Letournel E, Judet R. Fractures of the acetabulum. Berlin, New York: Springer-Verlag; 1993. 